\title{
research
}

\section{Sibling relationships and the construction of young people's gendered identities over time and in different spaces}

\author{
Rosalind Edwards, Sociology, Social Policy and Criminology, \\ University of Southampton, UK \\ r.s.edwards@soton.ac.uk
}

\author{
Susie Weller, Families \& Social Capital Research Group, Weeks Centre for \\ Social and Policy Research, London South Bank University, UK \\ wellers@lsbu.ac.uk
}

\begin{abstract}
This article explores the way that the assertion, negotiation and sanctioning of masculinity and femininity, and the construction and reconstruction of gendered identities and sexuality, are part of everyday relationships between brothers and sisters, located in time and place. This stands in some contrast to the dominant 'cause and effect' outcome model that characterises much research on sibling relationships. We use in-depth case studies drawn from a qualitative longitudinal study of young people's prescribed and chosen relationships to explore how continuities and changes in the markers and dynamics of gendered identities are embedded in and constructed through the ebbs and flows of sibling relationships over time and in specific locations.
\end{abstract}

key words siblings $\cdot$ gender identity $\cdot$ time $\cdot$ place

\section{Introduction}

Gender as a social category and as a lived and located relationship between men and women culturally, materially and psychically, is constructed through and structures every aspect of daily life. The way that children and young people think of themselves and act as sisters and brothers, girls and boys, and grow up to be women and men, is usually regarded as a vertical phenomenon. That is, how children 'develop' gendered identities and 'learn' what ways of thinking and behaving are acceptable or sanctioned as masculine or feminine, and how to relate to others on the basis of their gender, are treated conventionally as a result of the actions or temperaments of mothers and fathers, or shaped by dominant norms of masculinity and femininity conveyed through the media, youth culture and so on.

In this article we move away from dominant socialisation and developmental 'cause and effect' outcome models associated with studying sibling relationships, and from mainstream problem-focused or dysfunctional concerns that implicitly construct children and young people as passive outcomes. Rather, we highlight the ongoing 
construction of gender, and negotiation of masculinity and femininity, as part of brothers' and sisters' routine, and what are often thought of as trivial, interactions with each other in specific spaces and locations over time.

We begin with a brief review of recurrent ideas about the gender of siblings as both cause and effect, within a framework that largely poses parents as the central actors. We address some of the drawbacks of these dominant models. We then move on to consider alternative understandings of gender in sibling relationships, from feminist perspectives that highlight relationality, power, time and space, before providing four longitudinal case studies of children and young people's relationships with their sisters and brothers to illustrate how the construction, negotiation and contestation of gender and sexuality are embedded in their interactions, which are, in turn, rooted in and shaped by the spaces in which they occur. As Gorman-Murray (2008: 368) argues, 'the construction of gendered identities and power relations is spatialised'. The cases demonstrate both change and continuity over time in the quality and negotiation of gender between siblings. Such shifts over time, we argue, make it problematic to draw firm conclusions about the state and effect of relationships between sisters and brothers.

\section{Siblings and socialisation/development: gender as cause and effect}

Research on sibling relationships largely is interested in the socialisation of children and child development. ${ }^{1}$ Much of this work relates to family structure, encompassing a decontextualised, unlocated focus on parental characteristics such as education, income and occupation, and on structural features of the sibling family group often referred to as sibling 'configuration' or 'constellation', such as the number of children, birth order and spacing. Children's behaviour, attitudes, achievements and so on are then investigated in relation to the qualities of parents and composition of sibling groups (Steelman et al, 2002).

One way that the literature on siblings addresses gender is through researching the implications of the sex composition of sibling groups - the relative numbers of brothers and sisters in a family.This strand of work is more concerned with gender as a cause than as an outcome. Parents are placed as pivotal, in the number of children they produce and hence the balance of sexes within the sibling group. For instance, mothers whose first two children are of the same sex have been found to be more likely to go on to have a third child, while those who have two children of different sexes are more likely to stop at two (Iacovou, 2001). Parents are also assumed to be central in their gender-specific treatment of their children. For example, having opposite-sex siblings is said to have a negative effect on academic performance, which is then related, variously, to children's gender-specific needs being unsatisfied by parents, to parental expectations based on the gender composition of the sibling group and/or to parental preference for investment of scarce resources of time and money in male children in particular, who they calculate will repay the outlay (eg, Butcher and Case, 1994; Conley, 2000). Overall, though, verdicts on the findings about distinctions between parental treatment of siblings on the basis of gender are at best mixed (Steelman et al, 2002) or at worst almost non-existent (McHale et al, 1999).

Other work is concerned with gender as an outcome or effect, investigating the socialisation of sisters and brothers into respectively feminine and masculine attitudes and behaviour. While parents are posed as key agents in children's gender socialisation (McHale et al, 1992; Katz and Ksansnak, 1994), some work acknowledges that 
sisters and brothers may influence their siblings' socialisation through modelling and reinforcing feminine and masculine behaviour in a similar fashion to parents. Drawing on the idea of sibling configuration, older siblings are seen as especially active in this respect (eg, Sutton-Smith and Rosenberg, 1970). What are referred to as 'stereotypical' gender differences in the play activities and interactions of brother-sister, sister-sister and brother-brother pairs have also been identified (eg, Stoneham et al, 1986). McHale et al (1999) argue that in both these problem-driven scenarios, siblings are reinforcers of gender distinctions that are dependent on parents' attitudes towards masculinity and femininity - where parents hold traditional ideas and emphasise differences between their male and female children, then siblings will make these comparisons with each other as part of their daily life.

There are a number of shortcomings with studies of sibling relationships and gender associated with conventional socialisation and developmental paradigms. They include that these approaches place a hierarchical emphasis on parental influences or effects on children's gendered identities and sibling relationships.Young people are regarded as passive vessels and power within families is assumed unproblematically to flow from parent/s to child/ren. As a result, in a context where sisters and brothers often spend more time together in childhood than they do with their mothers or fathers, there is a neglect of the complex ways in which children and young people actively shape the gendered and other aspects of their own and their siblings' identities over time and in different spaces.

The predominant norms and ideas of conventional approaches to sibling research also overlook diversity within and between sibling relationships and the construction of gendered identities that flow from them. An abstract, universal development and socialised subject is constructed who is isolated from their particular familial, social, cultural, spatial and temporal contexts (Burman, 2001;James and James, 2004). Sparse attention has been given to changes and continuities, and the often complex and dynamic nature of gender and sibling relationships, identities and practices over time and in place.

\section{Alternative understandings of sibling relationships and gendered identities}

Gender as a social category and as an identity experienced by people both shapes and is shaped by every aspect of daily material and cultural life and institutional structures. Gendered identity and sexuality take place as part of sibling relationships. Gender is central to expectations of family roles and for the organisation of family lives. Children are clearly identified as male or female from the moment of birth (and before birth), with crucial importance for their family relationships and upbringing. In this respect, the significance of gender as a social structure has been a feature of feminist debate in an effort to expose how far gender as masculinities and femininities - and linked to this, sexualities - are products of social and cultural expectations and behaviours, rather than naturally and immutably fixed by biology. From a feminist psychoanalytic perspective, Mitchell (2003: 216) claims that the lateral relationships between siblings are relatively autonomous and just as, or even more, important than 'vertical' parent-child relationships in psychic and social learning, including in relation to masculinity and femininity: 'Gender is engendered in the sibling (or 
sibling equivalent) relationships'. For Mitchell, sibling relationships are critical for the process of understanding gendered and other forms of sameness and difference.

Feminist approaches often stress interdependency and how people's sense of self is relational; formed and shaped by interactions with other people. Studies of siblings that move away from a problem-centred approach often adopt a feminist relational starting point that is also informed by a child-focused perspective. These move us closer to understanding the processes of the construction, contestation and negotiation of gender that are part of brother and sister relationships. Examples include Song's $(1999,2008)$ exploration of the way that siblings of minority ethnic origin negotiate and monitor moral identities for themselves in contrast or correspondence to each other, including around appropriate, culturally defined masculine and feminine behaviour. Mauthner (2002) reveals the intricate dynamics of power and care at play in sister relationships across the lifecourse, from girlhood into womanhood, which are crucial to the development of feminine subjectivity. McNamee's (1999) work shows how gendered power relations between siblings are located, shaping their access to space and other facilities in their family home. And one of us, along with colleagues (Edwards et al, 2006), has examined the way that 'talk' and 'activity' are central gendered features of children's relationships with their brothers and sisters, revealing versions of femininity and masculinity within interplays of power in the locations of home, school and neighbourhood. A key message from such work, then, is the importance of the implicit and unnoticed ways in which gender is re/produced in and through routine and located life with siblings.

In what follows, we recognise young people as social actors in their own right, and focus on the processes of and contexts for their understandings and actions, including dynamics of power, time and space. This allows us to highlight the ongoing construction of gender, and negotiation of masculinity and femininity, as part of brothers' and sisters' everyday interactions with each other. Rather than an attribute attached to an individual sister or brother in a sibling relationship, power is understood as embedded in located relationships, subject to negotiation and contestation, and gendered identity as constantly constructed and reconstructed through and by social interactions. Masculinity and femininity are shaped by and subject to explicit and implicit affirmation and challenge, encouragement and sanction, as part of everyday exchanges that take place in particular spaces and places, which themselves are processes that are both bounded by and create social structures and divisions that legitimise some gendered and sexual identities, attributes and behaviours over others.

Sibling scholars often note that the sibling relationship is the longest-lasting relationship in people's lives - longer than relationships with parents, partners or children - although it may go through varying periods of closeness and distance (Dunn, 2008). This alerts us to the issue of time, and the way that relations between sisters and brothers can demonstrate aspects of change and continuity as they grow older. Much of the research within the dominant socialisation and development paradigms is indeed longitudinal, but concentrates on using survey methods to follow periods of childhood (eg, Baydar et al, 1997; Plomin et al, 2001). It tends to examine problematic, decontextualised cause and effect over periods of time, measured by particular outcomes, as discussed earlier. In contrast, in the case studies we now consider, we want to follow and illustrate the dynamics of changes and continuities over time and in different spaces that can occur in the construction, reproduction, 
negotiation and contestation of masculinity and femininity as part of siblings' everyday, taken-for-granted interactions, as they move from childhood towards adulthood.

\section{The 'Your Space' project: following sibling relationships over time}

The 'Your Space! Siblings and Friends' qualitative longitudinal research project (http:// www1.1sbu.ac.uk/ahs/research/yourspace/index.html) ${ }^{2}$ aims to document and track the meanings, experiences and flows of prescribed (sibling) and chosen (friendship) relationships for children and young people, and how these relate to their sense of self as their individual and family biographies unfold in context. It follows just over 50 children and young people, living across mainland Britain in various locales, from small villages in the Highlands of Scotland to towns in the South of Wales, former industrial areas in central England, suburban areas in the south of England and innercity London. They are males and females from a diversity of majority and minority ethnic backgrounds. They come from a range of social circumstances, advantaged and disadvantaged, and housing conditions that include temporary accommodation, public housing estates, suburban semi-detached homes and gated communities. They live in a variety of family formations, which means that as an overall sample their sibling relationships encompass both biological and social ties. Further, geographical, social and familial situations have shifted for some across the course of the study.

Our research is structured around repeat in-depth interviews conducted every few years with the children and young people in their homes. Topics that we have asked about over the decade that we have been following the young people's lives so far include:

- their relationships with their brothers and sisters;

- life at home, at school and in the neighbourhood;

- feelings of commonality and difference;

- times of help and support;

- times of argument and conflict.

The young people also participate in activities as part of the interviews that throw light on their sibling relationships, including tools such as circle maps, timelines and vignettes. (Details of our research process and practice, including sample selection, data collection and ethical approach, are discussed in Weller et al, 2011.)

The strength of qualitative longitudinal research is that it enables deep insights into the playing out of biographical and social processes in time and place. The purpose of such research is not to be representative of patterns in the population under study (here, young people who are siblings); rather, it is the provision of rich contextual information, often referred to as 'thick description', that enables temporal illumination of how relationships work in particular contexts. In this respect, case studies built on a data-led thematic analysis identifying significant statements and key meanings in an interview or set of interviews are a helpful vehicle for in-depth tracing of relationality in time and place, so we use them here. The following case studies of young people have been chosen because of the way they illuminate a topic that has been in the shadows: the construction and reconstruction of gendered identities and sexuality as part of everyday relationships between siblings in time and place. The cases throw light on the central argument of this article - that continuities and changes in the markers 
and dynamics of gendered identities are embedded in and constructed through the ebbs and flows of sibling relationships over time and in specific locations.

\section{Four case studies: siblings and gender over time}

In the following case studies we draw on interview data from waves 1 to 3 of our study, when our participants were aged 6-13 (2003 and 2005), 10-17 (2007) and 12-19 (2009). Data generation for wave 4 (aged 17-23, 2013) was completed recently. A few of our participants were not interviewed for all waves: two of our case studies draw on data from across all three waves of data collection, while two are based on material collected in two waves. ${ }^{3}$ The case study names are pseudonyms chosen by the participants themselves.

\section{Michael - continuity in gendered understandings}

Michael is a Black British boy, living with his socially mobile parents and older and younger brothers in inner-city London. At the time of the first interview with him, Michael was 12 years old and had just joined one of his older brothers - Joseph, aged 16 - at secondary school. In doing so, he moved from spending much of his time in a local co-educational primary school to a sought-after single-sex secondary school some distance from the family home.Joseph was playing a key part in Michael settling into the school, keeping a watchful, older brotherly eye and offering advice:

\footnotetext{
'At the beginning we used to go to school by ourselves ... and then instead of making me stay with him, he would tell me to go and talk to [people] and that I had to make friends with people. So he sort of pushed me on to make more friends.'
}

For the brothers the journey to school signified an important space; a time spent away from the controlled and structured environments of the home and school. It provided Michael with an arena in which he was able to develop his own sense of self as an individual, differentiated from his relational position as a brother in predominantly all-male environments.

By the second interview, Michael was 14, Joseph had just finished school and was going to university, and younger brother David, then age 12, was about to join Michael at his secondary school. Michael envisaged that he would be passing on experience and guiding David in the same way that Joseph had supported him: "I think you should help your brother ... it is good 'cos what you know could always help if you pass it on to your little brother ... you benefit from each other ... it makes school a bit easier if you're going with your brother."

Michael was 16 by the third wave of the research. His older brother Joseph was combining university with paid work, while younger brother David was still attending Michael's school. Michael continued to portray a strong sense of brotherly collectivity, posing flows of guidance and support as hierarchical. He discussed the passing on of care responsibilities, as well as expressing an increasing sense of responsibility for David's moral development: 
'I can remember my brother [Joseph] used to [prepare breakfast] for me and then he left and I had to take responsibility for doing my breakfast and my little brother's.... Make sure [David] doesn't step out of line and make sure anything he does wrong he knows he's done wrong and he sorts it out.'

Across these points in time, it was apparent that Michael's brothers were very significant in his life; a positive constant, always there and a source of fun. All three boys had led relatively structured lives, participating in similar activities such as sports, music and a boys club at various times. Over the years they co-constructed each other's (gendered) interests, frequenting and locating themselves and each other within the same spaces. They spent a significant proportion of their free time together playing computer games at home. Such key spaces in Michael's life were very much constructed along gendered lines. Within the home his mother, when not at work, occupied the kitchen on the ground floor of their home, while Michael and his brothers could often be found in the living room on the first floor, engaging in a range of technologies.

For Michael, these shared activities - primarily located in home and school spaces - alongside guidance, support, care and responsibility, down the brotherly age chain, were a demonstration of his connection to his siblings. This connection was definitively gendered in Michael's eyes. In the second interview he reflected on this issue:

'[If I'd had a sister] I think we would sort of be separate from her because she would have different hobbies, so I'd be more close to my brothers and because of the school I go to I wouldn't see her either because it's all boys. I sort of have this feeling that if you're older than your sister, and even younger, you're overprotective. And you learn and it sort of grows on you that you have to be really protective, and that dampens you enjoying yourself because you're always protecting someone.'

Thus, for Michael at age 14, while brothers would keep a watchful eye out for each other, this was with the aim of encouraging independence and resilience - as Joseph had done for Michael when he started at the same school, and Michael was going to do for David. In contrast, keeping vigilance over sisters was a brotherly responsibility that would never end - with the implication that sisters would not develop self-reliance. By 16, Michael still had strongly gendered ideas about brother-sister relationships, but this time focused more on gender as difference, posing sisters and brothers as distinct beings who could not communicate:

'I always wanted a sister but then I think, 'nah' 'cos it would be too much hassle because, if I had a sister, they'd almost definitely be completely different to me in like as they wouldn't be interested in the same things as I am.... 'Cos one of my friends has a little sister and he said that basically he just never talks to her. They're in the same house and could be in the same room but he wouldn't talk to her because they're completely different.'

Michael's case study illustrates the significance of shared activities and support-located in this instance mainly within the home and (single-sex) school settings - as markers of masculinity in relationships between brothers, especially passing down through the age hierarchy. A version of masculinity as protector is implicitly constructed and 
affirmed through Michael's relationships with his brothers. At points in time in his account, the hierarchical power flows associated with age, however, are overridden by gender, with Michael feeling the need to look after a sister, whether older or younger than him. Consistently across time, gendered difference between brothers and sisters shape his ideas about sibling relationships. Michael's case is also a good illustration of how understanding of relationships with siblings can demonstrate continuity in their gendered nature through times of lifecourse change such as moving into and through different spaces.

\section{Cora - shifting gendered dynamics}

The case of Cora is a contrast to the picture of continuity in understanding provided by Michael. When first interviewed, Cora was a 13-year-old White working-class girl, living with her 16-year-old brother Gordon, and their mother and father, in a small and isolated Scottish village with little in the way of transport links or facilities. The specifics of this rural location are significant in that the small close-knit community provided limited opportunities for youth leisure and independent mobility for young people was curtailed by poor public transport. These spatial contexts shaped and were woven into Cora's persistent raising of Gordon's apparent shortcomings throughout her interview. These deficiencies involved his everyday failure to act in the ways that she felt an older male sibling of hers should:

'He's just immature. He doesn't act like older... He can never say anything sensible ... I wish he'd go out more and act more like a teenager... 'Cos I've sort of grown up more faster than he is. He doesn't do anything basically. And he's just basically hanging around with people younger than him. 'Cos you know he never really asks if he can go up to [town].... Sad act.'

Cora herself would have gone out more if she could, but she was not allowed to travel into the nearest town on her own, while, perversely in her eyes, her brother could travel about on his own if he wanted to but he did not. Cora posed all her friends who had brothers as getting on far better with them than she did with hers.

Rurality has often been viewed as the locale for specific forms of traditional masculine gendered identities (Campbell and Bell, 2000; Little, 2002). Cora's account of her feelings for her older brother was replete with disappointment, contempt and ambivalence, and her reservations about Gordon's performance of an appropriate masculine identity were part of her concerns that he, and by association she, would be marked out as different in their small close-knit rural community. While, on the one hand, she could positively contrast her maturity as she embarked on teenagerhood with Gordon's immaturity, on the other hand, what she regarded as Gordon's wilful refusal to act in an appropriate masculine teenage way threatened to undermine her own rather fragile sense of emergent hegemonic teenage femininity. This is particularly significant in, and perpetuated by, the surveillance and lack of anonymity that constitutes many small isolated rural locales (Weller, 2007).

Four years on, their relationship had changed somewhat. Cora was 17 and her brother was 20, and they were both still living at home in the same village. Cora now felt that her friends who had brothers did not get on as well as she and Gordon did. She said they shared tastes in music and television, and thought that they had a 
similar sense of humour. Gordon sometimes picked her up from work and gave her a lift home in his car, and as a trainee hairdresser Cora cut his hair for him. Cora and her friends went out regularly with Gordon and his friends as part of a large group of young people from the nearby villages and town:

'[We started getting on] probably when I was 15 or 16,' cos a lot of our friends became friends with his friends. The group we go about with, it's all mixed ages.... We've both got a lot of friends.... There's nothing really I don't like about having a brother, it's fine ... I kind of class him as a friend as well.'

In Cora's eyes, Gordon's behaviour had become more appropriate for an older brother of hers - giving her lifts in his car, being far more outgoing and conforming to what she regarded as more acceptable local forms of masculinity. In turn she was able to demonstrate her feminine accomplishments in styling his hair. His new version of being an older brother meant that he was not only a sibling to her, but also a friend. She could now associate with him in ways that supported her own femininity rather than undermining it.

Cora's changing accounts illustrate how the dynamics of siblings' gendered sense of self, their femininity or masculinity, can be bound up with and negotiated in relation to each other as part of everyday situations. In this specific context of living in a remote village, the everyday involves the will and ability to travel about. Cora's case study also demonstrates how the negative or positive nature of gendered identities in sibling relationships is not fixed but can shift over time, here renegotiated as Gordon's actions and associated gender identity come to conform to acceptable (for Cora in her local context) ideas about masculinity.

\section{Florence and Isobel - persisting gendered identities and sexuality}

Florence and Isobel's case similarly shows how siblings' sense of gendered identity and sexuality can be crucially bound together, but this time demonstrates how this can persist in shape over time. These White middle-class sisters live in a small rural village in central England with their mother and stepfather. The village has seen much expansion in recent years, with the development of large housing estates. The sisters live on one such estate with few facilities and little in the way of public transport, rendering independent mobility challenging. Over the years, Florence and Isobel have spent much time together within the family home; a space significant in shaping their gendered and sexual identities. They have younger stepsiblings - Naomi and Marcus - from their father's subsequent relationship, who live in a large city in Southern England. The sisters' contact with them is infrequent.

The sisters were first interviewed as a pair when Florence was 11 and Isobel was eight. They talked at length about playing fantasy games at home in which Isobel chose to act out the popular, powerful and glamorous characters from traditional fairytales (eg, Cinderella, Princess), while Florence accepted the supporting, subservient or evil roles (eg, Evil Queen, Ugly Sister, Prince). Underpinning the sisters' play were gendered ideas associated with femininity and power, as the following exchange illustrates:

Isobel: '[Florence] doesn't really like to be the Princess.' 
Florence: 'I'm just not that kind of girl. I don't really like being the Princess in the top rank, I just like things the way they are. I mean, if I was a Princess I'd never be able to walk...'

Isobel: 'Florence is a bit fatter, Florence is a bit chubbier [than me].'

Florence: 'You're chubby, you're chubby'

Isobel: 'Florence is not a dressy skirt person. She wants to but first she's got to get rid of her chubby body...'

In this example the home becomes a space in which gender identities can be experimented with, contested, negotiated and/or reaffirmed.

The sisters' differential gendered identities in relation to each other remained relevant across the next two waves of interviews. Interviewed together again at age 12 and 15, Isobel remarked on Florence's lack of fashion sense and disinterest in makeup or boys, while Florence described herself as the 'fashion bag carrier' when they went shopping together. Two years later as a 14-year-old, Isobel derided Florence's current outfit in the joint interview.A 17-year-old Florence stated:"Well I often refer to Isobel as my style consultant. Basically if I'm going out somewhere special it will be kind of like, she says, 'Okay you've got to wear this, this and this'.'

Across time, the sisters consistently defined, positioned and accepted one another, respectively, as conforming to and rejecting of hegemonic femininity describing the spaces in which the display of such identities mattered. Isobel often sought to ensure that Florence conformed to some extent to a particular version of femininity in public spaces. Florence viewed Isobel as 'normal' and often referred to herself as 'weird', and while she regarded her own gendered positioning as awkward, she seemed to value it, particularly as time progressed. This became evident in her negative evaluation of her stepsister Naomi's conformity to dominant femininity - as opposed to making any criticism of Isobel's 'normality' - in the third-wave interview: "She kind of like embodies everything I hate. I just don't fit in with her ideal of how a person is meant to be. As I say, she's so normal and you've got to be into this and this."

Florence's perception of Naomi's desire to conform was highly spatialised. She could not understand Naomi's 'normal' feminine gender identity practice when she lived in a large cosmopolitan city where, Florence felt, difference could be more easily displayed and readily accepted than in her own locale. It seems that Florence resisted a particular construction of being female associated with her sister at wave 1 (not being that kind of girl) but later transferring this to her stepsister, enabling her to exist alongside and accept conventional femininity in her sister at waves 2 (as a fashion bag carrier) and 3 (receiving advice from the style consultant).

But the specifics of location were important in the ways the sisters related around femininity. It was in fact Isobel's 'normal' femininity that had enabled her to act as some support for Florence in reactions at school to her placement outside of conventional femininity. As Florence moved into her teenage years, she gained a reputation for ambivalent sexuality, at 15 recounting: "Someone asked whether I liked boys and I said, 'I don't know', and someone asked whether I liked girls and I said, 'quite honestly I don't know', because I hadn't done anything either way. So then everyone said that I was a bisexual and it's gone round the school." 
At that point, within the school locale, Isobel was able to draw on her own established sense of hegemonic femininity and heterosexuality, and the power associated with it, to support Florence in the face of such bullying. By wave 3, Isobel no longer needed to protect Florence; Florence was more self-assured about her identity, and the unpleasant remarks had stopped, albeit Florence commented that never having had 'a real boyfriend' still was considered 'weird'.

Florence and Isobel's case study provides a good example of the way that a causeand-effect approach can miss how gender is a lived relationship constructed through the shifting dynamics of the located and supposedly mundane interactions between siblings over time. It reveals how dominant versions of gendered identity and behaviour are bound up with power plays between sisters and in wider society - and vice versa, power play is bound up with gender - as well as demonstrating how ideas about gender identity and sexuality are linked together and negotiated. This case also points to the spatialisation of gendered identities and in particular the presentation and negotiation of gendered sibling identities at home, at school and in more public spaces within rural and urban environments.

\section{Marshall - continuity and change in masculinity, femininity and violence}

Change and continuity over time through the gendered ebbs and flows of sibling relationships are woven together in the case of Marshall. At 12 years old, Marshall, a White working-class boy, lived with his mother and baby sister, Ashleigh, in a small town in an isolated area of Wales. The town has undergone periods of great decline and during Marshall's lifetime has experienced high unemployment, deindustrialisation and urban decay. During his first interview, Marshall's older brother, John, then aged 17, occasionally lived in the family home. At that time, Marshall expressed clear distinctions between the nature and expectations of his relationship with his brother and sister. On the one hand, his relationship with John had been marked by aggression and abuse for some time. The violence directed at him by John caused Marshall to feel vulnerable not just physically but also emotionally. On the other hand, Ashleigh was providing Marshall with a sense of connection, care and affection - a safe person to relate to both physically and emotionally:

\footnotetext{
' 'Cos me and my brother don't get along that much.... It's like me and my sister get along well. I love my sister. I mean I do love my brother obviously, it's just the fact that I love my sister more. Because my brother always hits me.Anything really [can make it happen]. He mostly does it for fun. It made me feel lonely before my sister was there, but now she is here.... When she's being sick I get her a tea-towel, make her bottles, all that sort of thing.'
}

In Marshall's world, masculinity and violence were integrally linked and part of his relationship with his brother, while his baby sister's gender and age allowed him to express love and affection through the routine practices associated with baby care. Private home spaces can allow the negotiation of different masculinities where men can express themselves emotionally and engage in caring for children and domestic labour (Gorman-Murray, 2008). The arrival of his baby sister (and perhaps intermittent presence of his older brother) permitted Marshall to display an alternative version of masculinity, but only within the private space of his home. 
At 16, Marshall, his mother and sister had been joined by his mother's new husband, and change had also occurred in his relationships with John and Ashleigh. Marshall had grown much closer to John, who he saw on a daily basis and with whom he felt that he had much in common. Their masculine connection as brothers was now played out in primarily male-dominated leisure spaces through activities such as games of snooker and pool together, and sharing a taste for hardcore rave music, rather than through John's violence towards Marshall. It seemed that, four years on, Marshall had become his older brother John. He reflected on his similarities to John, which he saw as a result of having grown up and shared a home with him:

'[We are quite similar] personality-wise, yeah.... If we don't like someone we'll tell them.... We just talk the same, sound the same and we act the same.... [We've] grown up together [so it's] natural ... I just copied him, do you know what I mean, you just do when you're a kid, you copy your older brother.'

Marshall had acquired similar notions of masculinity and aggression to those he said were displayed by John when he was younger. He talked about the fights he was involved in between groups of young men in the neighbourhood, revealing the wider norms associated with being male in the locality and the embedded nature of particular forms of hegemonic masculinity in areas of deindustrialisation and high unemployment (Ward, 2013). Both Marshall and John continued to be involved in violence - but no longer towards each other.

Marshall's relationship with four-year old Ashleigh, by contrast, had become more characterised by aggression and - perhaps consequently - more peripheral emotionally. He had moved away from seeing her as a source of affection and object of care, and replaced this with the idea of a nuisance who shared his propensity for violence and taste for hardcore rave:

'When she's not in one of her moods yeah, we're fine. But normally she's just 'mum, mum, mum'. Clingy ... she's like me, she's got a short fuse.You've only got to look at her and stare at her and try and wind her up and she'll bite. She'll latch on and she'll scream and whinge and whatever.... Every time I put my music on, she'll dance'.

While John was no longer aggressive towards Marshall, this had been replaced by Ashleigh's responses to his provocation.

Marshall's account demonstrates a complex mix of both continuity and change in the associations between masculinity, femininity and violence, and associated emotional closeness and distance in sibling relationships over time and in different spaces. Differential flows of gendered power are in constant interplay for Marshall, as he renegotiates the construction of his identities as a brother to, respectively, his older brother and his younger sister, evidenced through the shifting relational meaning of taken-for-granted practices such as modes of speech as well as the more noticeable aggressive behaviour. 


\section{Messages about sibling relationships and gendered identities from longitudinal case studies}

It is important to emphasise that the four longitudinal case studies of children and young people's relationships with their sisters and brothers that we have presented this article are drawn from a diverse, everyday sample, rather than focusing on a particular group of children and young people who have been defined as problematic, with dysfunctional sibling relationships, and in receipt of intervention (although Marshall had seen an educational psychologist for a time in an attempt to manage his anger). This starting point has the strength of being able to provide us with everyday, located instances of gender in children and young people's ongoing relationships with their siblings - a commonplace rather than extraordinary picture of the construction, negotiation and contestation of gendered identity and sexuality between brothers and sisters.

It is also significant that our approach to looking at gender as embedded in and constructed through the dynamics of mundane and situated interactions between brothers and sisters over time and in different spaces, has been to take an alternative viewpoint that grounds itself in children and young people's own perspectives. The case studies are built from their accounts of their lives with their brothers and sisters, drawing out the ways in which siblings are active in constructing each others' gendered identities from these 'insider' understandings and experiences, rather than predetermining the constitution of gendered socialisation and 'normal' developmental trajectories from the outside. This has the strength of enabling us to see and focus on the processes of their understandings and actions, such as power and time in context.

An overriding and key message from the four longitudinal case studies of sibling relationships and gender from children and young people's own perspectives concerns their located and dynamic nature. Michael, Cora, Florence and Isobel, and Marshall each illustrate the varying particularities of changes and continuities over time that can occur in the construction, reproduction, negotiation and contestation of masculinity and femininity as part of siblings' everyday, taken-for-granted interactions, in specific spaces and places, as they move from childhood towards adulthood. This demonstration of situated change and continuity - often woven together and shifting about - directs us to acknowledge the difficulty of coming to substantive conclusions about the state and effect of everyday and ordinary relationships between sisters and brothers that apply universally regardless of context. There are no firm conclusions to be drawn here about any patterning of the construction and reconstruction of gendered identities and sexuality as part of sibling relationships, not least because the next wave of interview data in qualitative longitudinal research leaves open the possibility of shifts in biographical and social processes for each participant.

What the longitudinal case studies do offer is a reminder that gender is an important part of sibling relationships. They also provide a warning that it does not operate in a straightforward cause-and-effect manner. Rather, gender is embedded in brothers' and sisters' everyday, located interactions and constructed, negotiated and contested over time, with both changes and continuities. Indeed, a longitudinal approach shows how difficult it can be to predict how gender issues are going to play themselves out in sibling relationships. At various points in the case studies, we may identify problematic and worrying circumstances: 13-year-old Cora's contempt for her brother, Florence's clashes over her femininity with her sister at age 11 and taunts at school concerning 
her sexuality at age 15, and the violence that 12-year-old Marshall experienced at the hands of his brother. But none of these was a fixed situation in any simple or straightforward sense. It is important see a snapshot of a child or young person's life at a point in time as just that - a static moment. The life beyond that snapshot could be played out in any number of ways. Reinforcing this, placing a spatial lens on our analysis highlights how the negotiation and construction of gender identity are fluid and shift in different spaces (Little, 2002). Like many other types of relationship, sibling relationships demonstrate a complexity that means they are not amenable to universal prescription. As we re-engage with the lives of Michael, Cora, Florence and Isobel, and Marshall beyond the time covered in these case studies, and perhaps in different locations, as part of our ongoing longitudinal research, we expect to be reminded of the unexpected and fluid once again.

\section{Notes}

1 There is some work on sibling relationships and gender in middle and later adulthood, such as Green (2000), Connidis (2001) and Wright and Cassidy (2009).

${ }^{2}$ Wave 1 of this qualitative longitudinal study was funded as part of the Families \& Social Capital Economic and Social Research Council (ESRC) Research Group programme of work (M570255001) and by the Joseph Rowntree Foundation. Waves 2 and 3 were part of the ESRC Timescapes study (www.timescapes.leeds.ac.uk) (RES 43725 0003). Wave 4 of data collection is currently in the field (2013), funded as an ESRC National Centre for Research Methods' Methodological Innovation Project and explores the possibilities of online interviewing in qualitative longitudinal research.

3 The retention rates for waves 2 and 3 were $78 \%(n=67)$ and $90 \%(n=52)$ respectively.

\section{References}

Baydar, N, Greek, A, Brooks-Gunn, J, 1997, A longitudinal study of the effects of the birth of a sibling during preschool and early grade school years, Journal of Marriage and Family 59, 957-65

Burman, E, 2001, Beyond the baby and the bathwater: post-dualistic developmental psychologies for diverse childhoods, European Early Childhood Education Research Journal 9, 1, 5-22

Butcher, K, Case, A, 1994, The effect of sibling sex composition on women's education and earnings, Quarterly Journal of Economics 109, 531-63

Campbell, H, Bell, MM, 2000, The question of rural masculinities, Rural Sociologies, $65,4,532-46$

Conley, D, 2000, Sibship sex composition: effects on educational attainment, Social Science Research 29, 441-57

Connidis, IA, 2001, Family ties and ageing, Thousand Oaks, CA: Sage Publications

Dunn, J, 2008, Sibling relationships across the life-span, in M Klett-Davies (ed) Putting sibling relationships on the map: A multi-disciplinary perspective, London: Family and Parenting Institute, 16-29

Edwards, R, Hadfield, L, Lucey, H, Mauthner, M, 2006, Sibling identity and relationships: Sisters and brothers, Abingdon: Routledge

Gorman-Murray,A, 2008, Masculinity and the home: a critical review and conceptual framework, Australian Geographer 39, 3, 367-79

Green, R, 2000, Birth order and ratio of brothers to sisters in transsexuals, Psychological Medicine 30, 4, 789-95 
Iacovou, M, 2001, Fertility and female labour supply, ISER Working Paper 2001-19, Colchester: Institute for Social and Economic Research, University of Essex

James, A, James, A, 2004, Constructing childhood:Theory, policy and social practice, London: Palgrave

Katz, P, Ksansnak, K, 1994, Developmental aspects of gender role flexibility and traditionality in middle childhood and adolescence, Developmental Psychology 30, 272-82

Little, J, 2002, Rural geography: rural gender identity and the performance of masculinity and femininity in the countryside, Progress in Human Geography 26, 5, $665-70$

McHale, SM, Crouter, AC, Bartko, WP, 1992, Traditional and egalitarian patterns of parental involvement: antecedents, consequences and temporal rhythms, in D Featherman, R Lerner, M Perlmutter (eds) Lifespan development and behaviour, Hillsdale, NJ: Lawrence Erlbaum, 49-81

McHale, SM, Crouter, AC, Tucker, CJ, 1999, Family context and gender role socialization in middle childhood: comparing girls to boys and sisters to brothers, Child Development 70, 4, 990-1004

McNamee, S, 1999, 'I won't let her in my room': sibling strategies of power and resistance around computer and video games, in J Seymour, P Bagguley (eds) Relating intimacies: Power and resistance, Basingstoke: Macmillan, 246-60

Mauthner, M, 2002, Sistering: Power and change in female relationships, Basingstoke: Palgrave

Mitchell, J, 2003, Siblings, sex and violence, Cambridge: Polity Press

Plomin, R,Ashbury, K, Dunn, J, 2001,Why are children in the same family so different? Nonshared environment a decade later, Canadian Journal of Psychiatry 46, 225-33

Song, M, 1999, Helping out: Children's labor in ethnic businesses, Philadelphia, PA:Temple University Press

Song, M, 2008, 'Mixed race' siblings and racial identification, in M Klett-Davies (ed) Putting sibling relationships on the map: A multi-disciplinary perspective, London: Family and Parenting Institute, 82-97

Steelman, LS, Powell, B, Werum, R, Carter, S, 2002, Reconsidering the effects of sibling configuration: recent advances and challenges, Annual Review of Sociology 28, 243-69

Stoneham, Z, Brody, G, MacKinnon, C, 1986, Same-sex and cross-sex siblings: activity choices, roles, behaviour and gender stereotypes, Sex Roles 15, 494-510

Sutton-Smith, B, Rosenberg, BG, 1970, The sibling, New York, NY: Holt, Rinehart and Winston

Ward, MRM, 2013, The performance of young working-class masculinities in the South Wales valleys, doctoral thesis, Cardiff University, http://orca.cf.ac. uk/47177/1/Mike\%20Ward\%20FINAL\%20Thesis\%20May\%202013\%20pdf.pdf

Weller, S, 2007, Teenagers' citizenship: Experiences and education, Oxford:RoutledgeFalmer

Weller, S, Edwards, R, with Stephenson, R, 2011, Researching children's lateral relationships over time: Methodological and ethical lessons from a qualitative longitudinal study, Families \& Social Capital Research Group Working Paper no 30, London: London South Bank University

Wright, L, Cassidy, T, 2009, Family structure and environment in psychological adjustment, paper presented at the British Psychological Society annual conference, Brighton, 2 April 